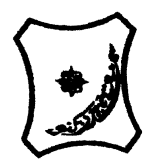

Bayero Journal of Pure and Applied Sciences, 14(1):221 - 229

Received: April, 2021

Accepted: May, 2021

ISSN $2006-6996$

\title{
INTEGRATING INFORMATION AND COMMUNICATION TECHNOLOGY (ICT) IN SOCIAL INTERACTION SPACES OF PROPOSED PUBLIC LIBRARY GWAGWALADA, ABUJA-NIGERIA
}

\author{
${ }^{1}$ Yahaya, M. M. and ${ }^{2}$ Abdullahi,A. \\ ${ }^{1}$ Department of Architecture, Ahmadu Bello University, Zaria. \\ ${ }^{2}$ Department of Architecture, Ahmadu Bello University, Zaria. \\ 1Mymaikano@yahoo.com²Abdulubale@yahoo.co.uk
}

ABSTRACT

This work focuses on preference of Public Library users on information and communication technology (ICT) facilities that matches user social activities in the library. It also proffers means of integrating such factors in social interaction spaces of proposed Public library Gwagwalada, Abuja to enhance user experience and meet the digital age. Libraries began incorporating ICT facilities since the advent of technology but without considering the facilities that matches user activity in such spaces. The analysis is based on data collected through observation and questionnaire survey addressed to users and staff of three public libraries and analyzed using SPSS and Microsoft Excel analytical software. The results show that Group Creative Collaborative space is more preferred by users while very few users prefer Small Group Collaborative space. Responses indicate that users prefer group studies to interact. Also "Between Individual and Individual spaces", majority of public library users prefer Internet Facilities which appears to have mean of (3.8371) while very few prefer Video Conferencing with mean of (2.8708).It also reveals that, in "Between Group and Group space" majority of public library users prefer Mailing List with mean of (3.7247) while very few users prefer Video Conferencing with mean of (3.0955) and "Between Group and Object space" majority of the users prefer Digitalized Library Structure with mean of (3.6180) while very few users prefer interactive floor (iFloor) with mean of (3.1292).In conclusion ICT has high potential for encouraging social interaction, in public spaces, thus connecting the society and provides access points to information and supports education. The study revealed the current situation on the issues investigated which can be relied on in future studies or decision making. Essentially, the study produced findings that researchers can apply or validate subsequent similar researches.

Keywords: Information and Communication Technology (ICT), Social Interaction Spaces, Public Library, Integration.

\section{INTRODUCTION}

Public libraries have become global destinations, hosting festivals, conferences, and events attracting people from around the world (Martin, 2016). They are places where individuals meet new friends to explore ideas and share interests across social and intellectual boundaries. Therefore, it should be a place for people to freely interact; flexibility and adaptability, must be modifiable reflect people's changing interests. Libraries are meant to inspire lifelong learning, advance knowledge, and strengthen our communities (Connie, 2015). The primary role of public library such as State Library, District Library, Block Library, Village Library and others is to provide the best information facilities to all those in the community (Ndumet al., 2012). Mary and Sara (2017) explained that in 2006, Bennett made a convincing case for thinking about library users "information consumers" as learners and "library service space" as learning space. His ideas have controlled many librarians to reconsider the role of learning theory in the planning of library spaces. Ten years later, Brian (2016) described libraries as hives of activity. These ideas combined together paint a complex library landscape focused on a variety of informal learning spaces designed to motivate users to learn. With the advent of technology, many libraries are appreciating social interaction spaces through ICT (Danielle et al., 2015). 
BAJOPAS Volume 14 Number 1,June, 2021 Rajanikant (2018) opine that library is one of the main areas deeply impacted by ICTs. Through automation, there has been an increase in the number of patrons going to the library for various purposes (Ndum et al., 2012). In fact, it is now difficult to imagine a society without information technology, which therefore cannot be overlooked. The society's educational exploration, social cohesion and access to educational materials apart from school is the public library (Librarian's Registration Council of Nigeria [LRCN], 2015). Therefore, learning spaces need to be designed with an understanding of how they will be easily utilized by users from isolated to collaborative study with enhanced technology that suits users (Lucy et al., 2018).

Today's Libraries are not only affected by level of technology but rather employing the right technologies users require in various spaces. Also, Tunde and Fausat, (2018) explains that no library no matter how well equipped does not require the service of functional ICT facilities.

Based on preliminary survey it has been observed that Gwagwalada Local government area population as at 2006 was 158,618 and projected to be 402,000 by 2016 . According to Librarian's Registration Council of Nigeria (LRCN) and International Federation of Library Associations and Institutions (IFLA) population up to 10,000 require a public library (LRCN, IFLA, 2015). Also, based on review it was observed that studies on social space and ICT in Public libraries have been carried out by Afolabi and Abidoye (2011); Muhammad (2014); Warikam (2012); and Ayman et al., (2016), the researches focused on improving social spaces and upgrading the library but do not consider the specific ICT features users prefer within each social spaces to match their activities. In the current digital age where almost all libraries are evolving to use of ICT features, it has become difficult to understand the specific ICT facilities that fits the social spaces. The lack of Public
Library that integrates ICT facilities that matches user preference in the social space will limit the ease and faster ways to interact with the library (Ayman et al., 2016).

However great attention is paid to the ICTs while ignoring the preference of user in determining the social spaces (Muhammad, 2014). Little attention has been given to integrating ICT user preference in the social spaces of public library (Warikam, 2012). Effective learning spaces tend to allow users to work collaboratively and enhance their cognitive functioning (Yahaya and Abdullahi, 2018). If professionals respond to the community's needs, then the public library service will survive (Gemma, 2016). This research will respond to users' needs through integrating ICT in the social interaction spaces of public libraries. Therefore, the study will identify the factors that could facilitate the integration of ICT in social spaces of proposed Public library Gwagwalada, Abuja to enhance user experience and meet the digital age for effective delivery.

\section{The Concept of Social Interaction in Relation to Public Libraries}

According to Umar (2014), social interaction is the general process whereby two or more persons are in a meaningful contact, as a result of which their behavior is modified. Umar, (2014) further classified elements of social interaction as; (a) Two or more than two persons, (b) Reciprocal relationship among them (c) Influence on the event, behavior, brain of the persons. These three conditions interrelate people among themselves and convert them into social groups. There are two types of social interaction between people and societies as stated by Umar (2014) which are Direct or physical interaction and Symbolic interaction.

\section{Functions of Social Interaction Between} Individuals

Karel et al.(2003) categorized the functions of social interaction into two namely; cognitive process and socio-emotional and social process as shown diagrammatically below;

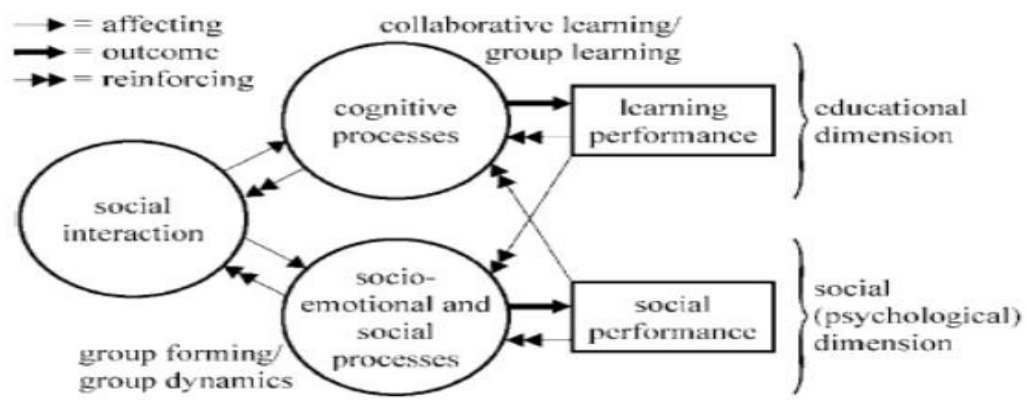

Figure 1: Functions of social interaction spaces. Source; (Shonhe, 2017). 
BAJOPAS Volume 14 Number 1,June, 2021 The functions of social interaction are divided into two aspects, the first is the cognitive process which leads to learning performance through collaborative learning/group learning and subsequently all lead to the outcome of educational dimension. While the second socioemotional and social process which leads to social performance and onto social (psychological) dimension.

Forms of Social Interaction in the Library

The forms of social interaction are classified as; Between individual and individual, between individual and group, Between group and group and between group and object. Oliver et al. (2015) further categorized the forms of social interaction learning within study area in the library as; small group collaborative space, medium size collaborative space, large format collaborative space, group creative collaborative space, enclosed soundproof space and multifunctional mix use space.

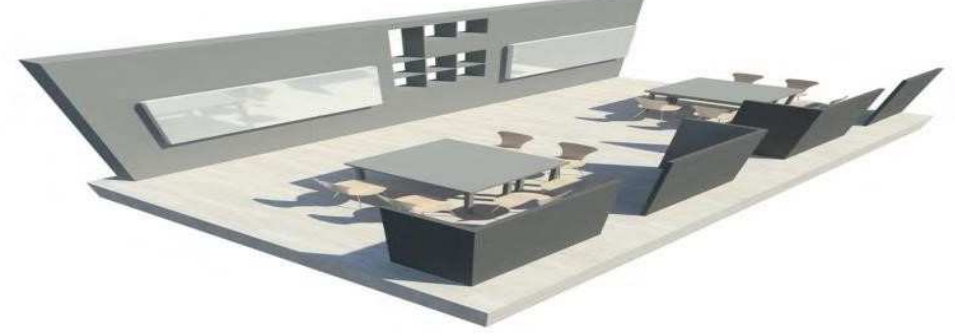

Figure 2: Group creative Collaborative space. Source; (Oliver et al., 2015).

Information and Communication Technology (ICT) Development in Public Libraries. Public libraries were initially designed to provide everyone with access to printed books. As print books have become cheaper, public libraries have been filling up with them and they are now said to be 'overrun' with books (Gemma, 2016). Now public libraries are providing access to material online. Libraries are becoming platforms that support a diverse range of ICT activities (Danielle et al., 2015). ICT tools are being used in Libraries to manage library more efficiently and as well cater for users' information need more effectively (Rajanikant, 2018).

\section{ICT User Requirement in Public Library Operations and Services}

The use of ICT has impacted on library services according to Igbeka et al. (2010) in the following ways: No physical boundary, storage capacity and preservation. Ekeanyawu and EdeworIt (2009) argued that not only do ICT saves time but guarantees accuracy, efficiency and distribution of information. Afolabi and Abidoye (2011) categorized ICT Facilities in Library Operations as: Computer, Internet facility, Networks, Video conferencing, Expert system and Electronic mail (E-mail). Also Martin (2016) and Warikam, (2012) added the interactive floor (ifloor) and interactive walls alongside others. They include ifloor, Interactive walls, Online, reference services, Library web sites, online public access catalogues and networked databases, Short message service (SMS) notification, Personal space/My Library, Quick response (QR) codes, Online VOD (MVOD), Mailing lists and Social media networks.

Data collected for the study was through mix method approach. Similar studies suggested and used this approach and were able to produce useful and effective results.

\section{RESEARCH METHODOLOGY}

The research employed mainly mix method to study the integration of ICT in social spaces of National library of Nigeria, Abuja; Murtala Muhammed library, Kano; Kaduna state public library and Battery park city library, USA. Population in this study include users of Public Libraries while selected users of Public Libraries were chosen as the target population for the research. Four hundred respondents were selected from the libraries using purposive sampling technique from the target population. This is supported by the methods used in previous similar studies such as: Esther, n.d; Muhammad, (2014); Warikam, (2012); Tunde and Fausat, (2018); Kumar and Bhatt, (2015); Adeleke, (2017). Observation survey was used to address the first objective while questionnaire survey was used to address the second objective. Also questionnaire survey and observation survey was used as primary data while the instrument of data collection was checklist schedule and schedule of questions consecutively. For secondary data, literature review was used and instrument for data collection was past positive documents. This is in line with previous similar studies of Adeleke, (2017); Muhammad, (2014) and Tunde and Fausat (2018). 
BAJOPAS Volume 14 Number 1,June, 2021

Checklist in line with a total of 400 questionnaires were administered to the respondents, 395 were returned, 5 were missing and 8 were invalid. Data were analyzed using SPSS and Microsoft Excel software due to the nature of the data. The data was translated into numeric codes by the researcher and analyzed into descriptive statistics.

\section{DATA PRESENTATION AND DISCUSSION}

This section presents the result of analysis of the data collected from various respondents. Outcome of the findings will be presented alongside background of the respondents.

Results and Discussion

\section{Students' demographic data}

From the sample size, a total number of 400 questionnaires were administered but only 387 were found useful and analyzed.

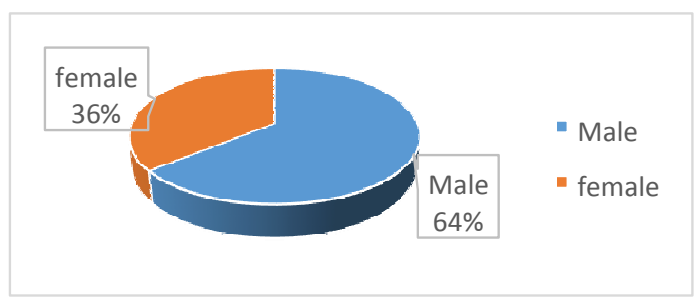

Figure 3: Respondent's Gender

This shows that $64 \%$ (114) respondents (males) visit public library more than female users with $36 \%$ (64) respondents.

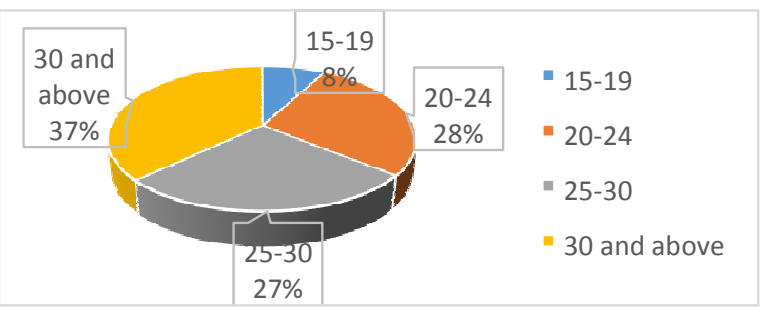

Figure 4: Respondent's age range

This shows that majority of Public library users are those within the age range of 30 years and above with $37 \%$ (66) respondents while the minority are those with the age range of $15-19$ years with $8 \%$ (14) respondents.

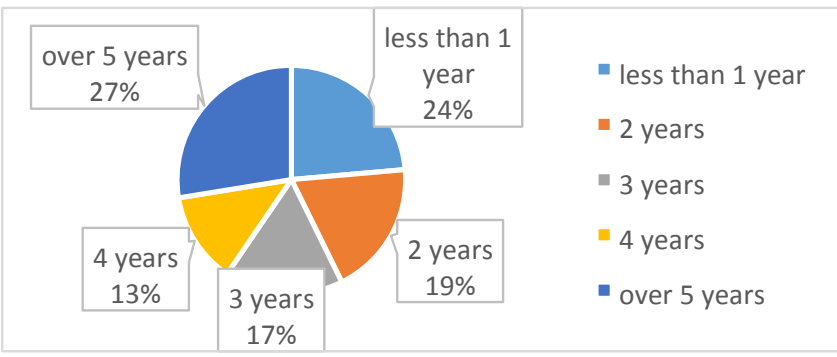

Figure 5: Respondents Duration of visit

This shows that most of the respondents to this study have been visiting the library for over 5 years with $27 \%$ (49) respondents. This will provide needed and validated result.

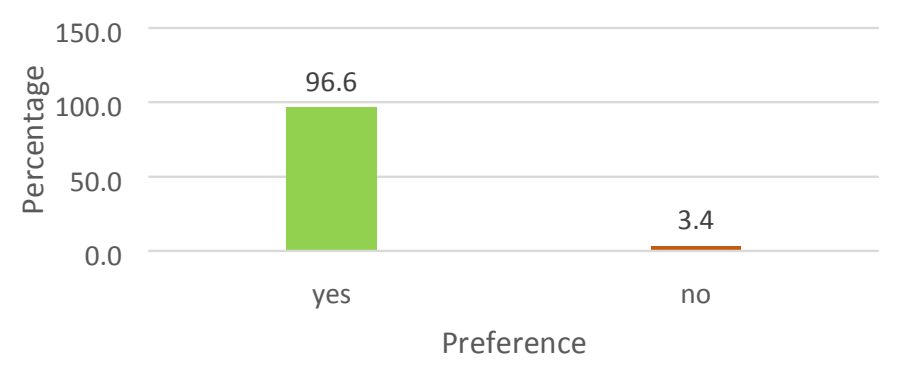

Figure 6: If users enjoy spending much time in the Public Library. 
BAJOPAS Volume 14 Number 1,June, 2021

This shows that majority of the respondents enjoy spending much time in the public library with $96.6 \%$ (172) respondents while few do not enjoy spending much time with $3.4 \%$ (6) respondents.

Respondents Perception of ICT and Manual System

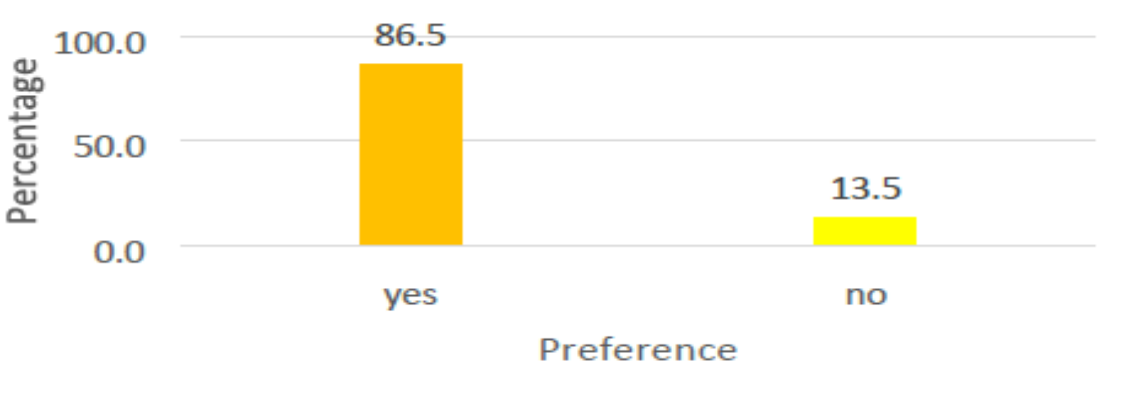

Figure 7: Respondents preference of ICT and Manual system

This show that majority of the respondents prefer ICT system with $86.5 \%$ (154) respondents rather than manual system with $13.5 \%$ (24) respondents in the public library.

\section{Respondents Perception of Social Interaction Spaces in Public Library}

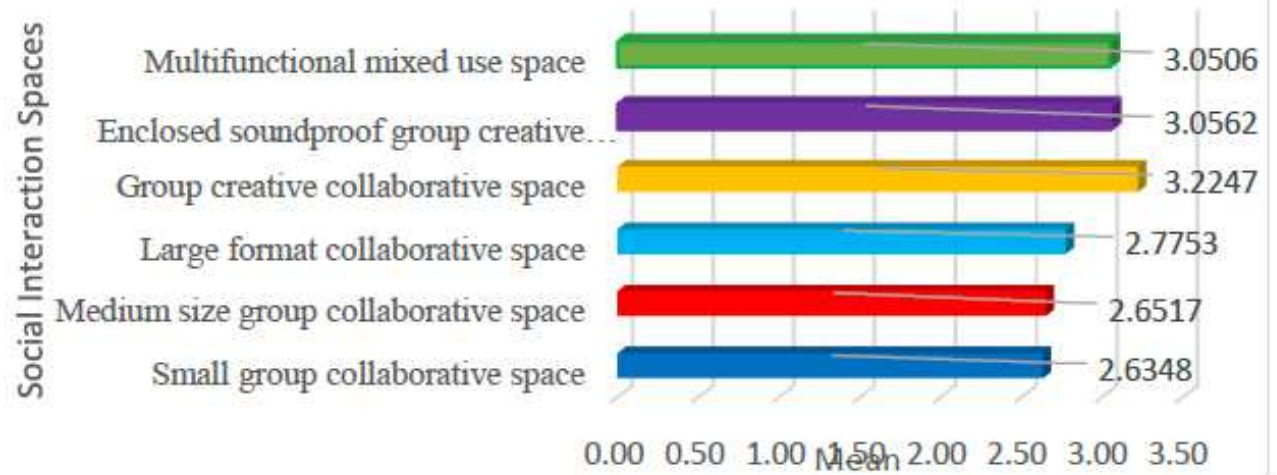

Figure 8: Respondents preference of Social Interaction Spaces.

This shows that Group Creative Collaborative space is much appreciated by users for social interaction in the public library with mean of 3.2247 while very few users prefer Small Group Collaborative space in the public library with mean of 2.6348 .

Respondents Perception of ICT User Requirement in Public Libraries

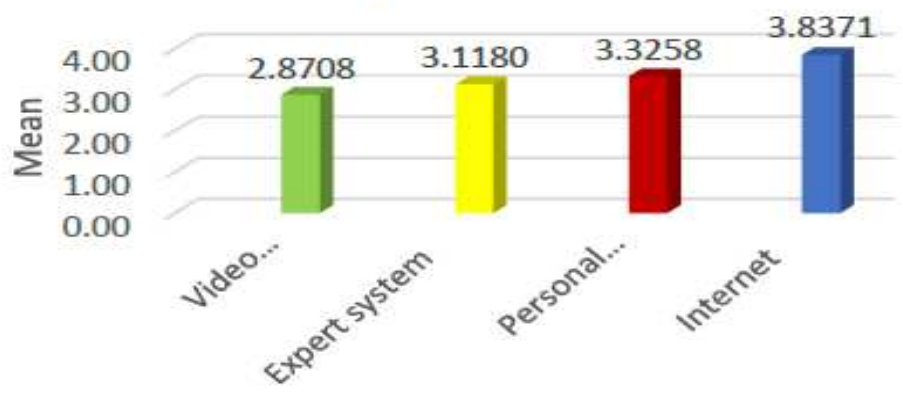

ICT Features

Figure 9: Respondents preferred ICT facility in "Between Individual and Individual" space.

ICT facility preferred in "Between Individual and Individual space" by users show that majority of public library users prefer Internet Facilities with mean of 3.8371 followed by Personal space/My Library, followed by Expert system and then very few of the users prefer Video Conferencing with mean of 2.8708 . 
BAJOPAS Volume 14 Number 1,June, 2021

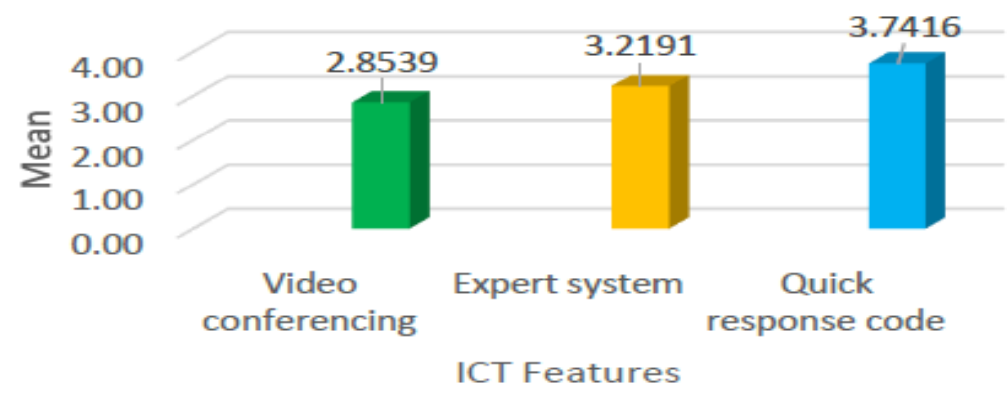

Figure 10: Respondents preferred ICT facility in "Between Individual and Group" space.

ICT facility preferred in "Between Individual and Group space" by users show thatmajority of public library users prefer Quick Response Code with mean of 3.7416 followed by Expert system, and very few of the users prefer Video Conferencing with mean of 2.8539 .

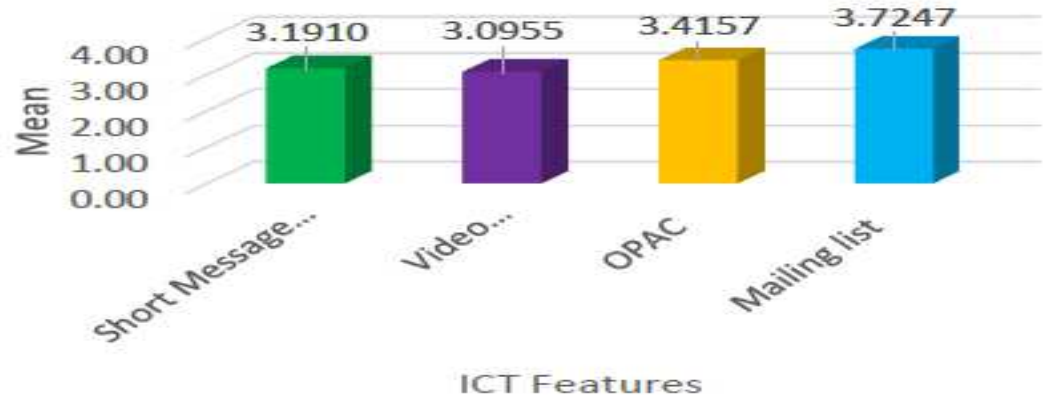

Figure 11: Respondents preferred ICT facility in "Between Group and Group" space.

ICT facility preferred in "Between Group and Group space" by users show that majority of public library users prefer Mailing List with mean of 3.7247 followed by Online Public Access Catalogue (OPAC), followed by Short Message Service (SMS) and then very few of the users prefer Video Conferencing with mean of 3.0955 .

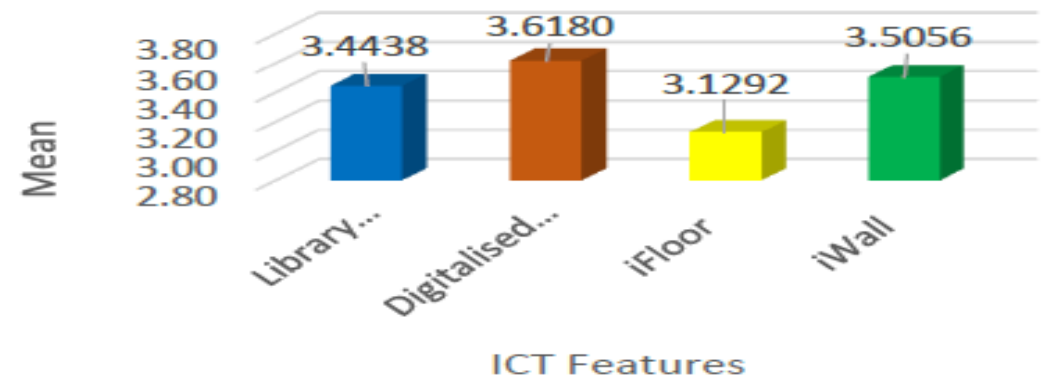

Figure 12: Respondents preferred ICT facility in "Between Group and Object" space.

ICT facility preferred in "Between Group and Object space" by users show that majority of public library users prefer Digitalized Library Structure with mean of 3.6180 followed by interactive wall (iWall), followed by Library web sites and then very few of the users prefer (iFloor) with mean of 3.1292.

\section{DISCUSSION}

Findings from the study reveal that ICT facilities tend to be only provided at group creative collaborative space in some Public Libraries to enhance interaction. While in others none of these spaces are provided with ICT except in individual spaces. 
BAJOPAS Volume 14 Number 1,June, 2021 Findings from the study also reveals that the respondents to this study are users of Public Libraries and that male users visits public library more frequent than female users which supports McCabe \& Kennedy (2003). Also the study reveals that most of the respondents are within the age range of 30 years and above and most of the users have been visiting public libraries for over 5 years to carry out different tasks and activities. Also majority of the users like to spend much time in the public library due to its level of comfort and ICT system is far more preferred by respondents than manual which supports Satpathy and Maharana (2011) and Tunde et al., (2018).

The study reveals that Group Creative Collaborative space is much appreciated by users followed by enclosed sound proof space, multifunctional mix use space then large format collaborative while very few users prefer medium size collaborative space and small group collaborative space. This indicate that users prefer large group study spaces. This supports Kastanakis et al. (2014).

Findings also indicate that in "Between Individual and Individual space", majority of public library users prefer Internet Facilities with mean of 3.83 which will enable them access the internet at all times and with strong signal to access information in order to enhance social interaction this is in line with Shonhe (2017) while very few prefer Video Conferencing with mean of 2.87 to enhance social interaction in public Libraries. It also indicates that, in "Between Individual and Group space" majority of public library users prefer Quick Response Code with mean of 3.74 to allow users to be directed to relevant sites and pages relevant to their search in order to enhance social interaction while very few prefer Video Conferencing with mean of 2.85. It also reveals that in "Between Group and Group space" majority of public library users prefer Mailing List with mean of 3.72 which will allow users to send and receive a list of mail containing questions and answer in such space to enhance social interaction while very few prefer Video Conferencing with mean of 3.09 to enhance social interaction in public Libraries. Also, majority of public library users in "Between Group and Object space" majority of the users prefer Digitalized Library Structure with mean of 3.61 which will allow users to operate the building structure like a machine instead of manually followed by interactive wall (iWall), followed by Library web sites and then very few prefer (iFloor) with mean of 3.12 to enhance social interaction in public Libraries.

In line with previous researches, Satpathy and Maharana (2011) and Tunde et al., (2018) supports the finding that ICT system is far more preferred by respondents than manual system while McCabe and Kennedy (2003) supports the finding that male users visits public library more frequent than female users. Also the finding that users prefer large group study spaces is supported by Kastanakis et al.,(2014). In addition, "Between Individual and Individual space", majority of public library users prefer Internet Facilities which will enable them access information from the internet with strong signal. This is in line with the finding of Shonhe (2017).

\section{CONCLUSION AND RECOMMENDATION}

In conclusion ICT has a high potential for encouraging social interaction in public library. The use of ICTs can significantly enhance public space, by creating access points to information and supporting education. The study also revealed the current situation on the issues investigated which can be relied on in future studies or decision making. Essentially, the study produced findings that researchers can apply or validate subsequent similar researches. Provision of group social spaces is essential as group spaces will always be occupied. This should serve as background knowledge to researchers and professionals concerned in designing Libraries. Such spaces should be highly encouraged and incorporated with proper ICT features in libraries to meet the need of users. Planners must go back to the basics of good design, while assessing the specific technological needs. Also government should provide means to maintain such facilities to meet up with the digital age $\left(21^{\text {st }}\right.$ century) for effective delivery. Public Libraries that integrates ICT facilities that matches user preference in the social space will enhance the ease and faster ways to interact with the library, aid social cohesion and subsequently increase patronage to fully harness the library resources.

\section{Acknowledgement}

The authors would like to thank users and staff of National Library of Nigeria Abuja, Kano state public Library and Kaduna state Public Library for their contribution to this research. 
BAJOPAS Volume 14 Number 1,June, 2021 REFERENCES

Adeleke, O. (2017). An Investigation of the Extent of Automation of Public Libraries in South West Nigeria.[Master's thesis, university of KwaZulu-Natal, Pietermaritzburg]. School of social sciences, college of humanities, university of KwaZulu-Natal, Pietermaritzburg, South Africa.

Afolabi, A. andAbidoye, J. (2011). The integration of information and communication technology in library operations towards effective library services. Proceedings of The 1st International Technology, Education and Environment Conference: African society for scientific research (ASSR). Adeolaafolabi86@yahoo.com.

Ayman, A., Abdel-Aziz, H. \& Zeyad, E. (2016). The role of ICTs in creating the new social public place of the digital era. Alexandria Engineering Journal, 55, p. 487-493.

Bennett, S. (2006). Winning back the public spaces. Conference lectured at the symposium (In) visible Cities. Spaces of hope, spaces of citizenship. Center of contemporary culture of Barcelona.

Brian, S. (2016). A design model for lifelong learning networks. Interactive Learning Environments, 13(1-2), p. 71-92. https://doi.org/10.1080/1049482050017 3656

Connie, M. (2015). Cultural preservation through public libraries. Lessons from Kanye Public Library.

Danielle, W., Scott, M. \& Danny, B. (2015). Public libraries in a digital culture: The research unit in public cultures school of culture and communication the university of Melbourne.

Ekeanyawu, N. and Edewor, A. (2009). Cultural implications of ICTs and globalization in the Nigerian society. JCMR Journalof Communication and Media Research, I (2), p. 1329. Rapid research \& communications Ltd.

Gemma, J. (2016). Designing libraries in 21st century: lessons for the UK. Winston churchil memorial trust, British council.

Igbeka, O., Adebisi, A. and Uwaifor, A. (2010). Enumerated impact of information and communication technology (ICT) in Library operations and services thus: from pp. 2-8

International Federation of Library Association [IFLA] (2010). Public library service guidelines. de Gruyter Saur.
Karel, K., Paul, A. and Wim, J. (2003). Identifying the pitfalls for social interaction in computer- supported collaborative learning environments: A review of the research. Computers in Human Behavior, 19, p. 335-353.

Kumar, A. and Bhatt, K. (2015). A Study of using informal learning spaces at Indian institute of technology. Library Philosophy and Practice (ejournal),p.1239. http://digitalcommons.unl.edu/libphilpra c/1239.

Librarian's Registration Council of Nigeria [LRCN], (2015). Federal ministry of education: Standards and guidelines for public libraries in Nigeria. http://www.eifl.net/news/ten-newlibrary-serviceschildren-and-youth

Lucy, M., Gabrielle, M., Rachel, W. and Bronwyn, C. (2018). Belonging in space: informal learning spaces and the student experience. Journal of Learning Spaces, $7(2)$, p. 13-22.

Yahaya, M.M. and Abdullahi, A. (2018). Students satisfaction of indoor learning environment of Ahmadu Bello University, Zaria: A case study of department of Architecture. Dutse Journal of Pure and Applied Sciences (DUJOPAS), 04(01), p. 17-28.

Martin, L. (2016). Designing for social use in public places: A conceptual framework of social interaction. Aarhus school of Architecture, institute for design, center for interactive space Abogade 34, 8200. martinl@interactivespaces.net

Mary, S. and Sara, B. (2017). Academic library spaces: Advancing student success and helping students thrive. Portal Libraries and The Academy, 17(2), p. 390-402. Johns Hopkins University Press, MD 21218.

Muhammad, K. (2014). Evaluating User Needs in The Design of Public Library, Kaduna: Integrating Cyber Community. [Master's thesis, Ahmadu Bello University Zaria]. Department of Architecture, faculty of environmental design, Ahmadu Bello University Zaria Kaduna, Nigeria.

McCabe, G. B., and Kennedy, L. (2003). Planning the modern public library building. The libraries unlimited library management collection, greenwood publishing group.

Ndum, V., Edem, E., and Chinwe, G. (2012). Library digitization: A panacea for educational development in Nigeria. Journal of Humanities and Social Science (JHSS), 5(2), p. 21-28. 
BAJOPAS Volume 14 Number 1,June, 2021

Oliver, O., Andrew, K. and Steve, D. (2015). Space planning and the re-invention of the library. University of Sunderland. SCONUL

Rajanikant, P. (2018). Information and communication technologies based best practices in library. IP Indian Journal of Library Science and Information Technology, 3(2), p. 101-105. https://doi.org /10.18231/24569623.2018.0022.

Shonhe, L. (2017). A literature review of information dissemination techniques in the $21^{\text {st }} \quad$ century era. Library Philosophy And Practice (E-Journal). $\quad$ P. 1731. https://digitalcommons.unl.edu/libphilpr ac/1731.

Tunde, T., Fausat, A., andLawal, M. (2018). Assessment of information and communication technology competencies of library staff in selected universities in Kwara state, Nigeria. Library Philosophy and Practice (E-Journal) p. 1797. https://digitalcommons.unl.edu/libphilpr ac/1797.

Umar, F. (2014).A study lecture notes management and social sciences; social interaction, definition, elements, types and forms. www.google.com

Warikam, E. (2012). Envisioning The Abuja Public Library as Means for Social Interaction.[Master's thesis,Ahmadu Bello University Zaria]. Department of Architecture, faculty of environmental design, Ahmadu Bello University Zaria Kaduna, Nigeria.

WBDG, (2017). Whole building design guide; National institute of building sciences. Innovative solutions for built environment. www.google.com. 